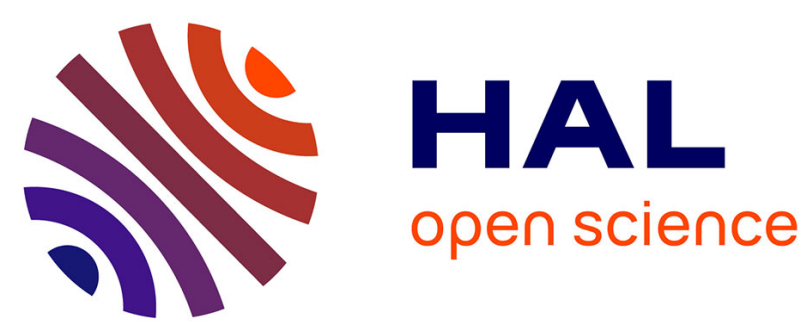

\title{
Effects on colour discrimination during long term exposure to high altitudes on Mt. Everest
}

Gabriel Willmann, Iliya V Ivanov, Manuel D Fischer, Sukhamay Lahiri, Rohit K Pokharel, Annette Werner, Tejvir S Khurana

\section{- To cite this version:}

Gabriel Willmann, Iliya V Ivanov, Manuel D Fischer, Sukhamay Lahiri, Rohit K Pokharel, et al.. Effects on colour discrimination during long term exposure to high altitudes on Mt. Everest. British Journal of Ophthalmology, 2010, 94 (10), pp.1393. 10.1136/bjo.2009.178491 . hal-00568504

\section{HAL Id: hal-00568504 https://hal.science/hal-00568504}

Submitted on 23 Feb 2011

HAL is a multi-disciplinary open access archive for the deposit and dissemination of scientific research documents, whether they are published or not. The documents may come from teaching and research institutions in France or abroad, or from public or private research centers.
L'archive ouverte pluridisciplinaire HAL, est destinée au dépôt et à la diffusion de documents scientifiques de niveau recherche, publiés ou non, émanant des établissements d'enseignement et de recherche français ou étrangers, des laboratoires publics ou privés. 


\section{Effects on colour discrimination during long term exposure to high altitudes on Mt. Everest}

Correspondence to:

Gabriel Willmann, Eye Hospital, Centre for Ophthalmology, University of Tübingen, 72076 Tübingen, Schleichstrasse 12-16, Germany; Gabriel.Willmann@med.unituebingen.de; phone: 0049 (0)17662245750, fax: 0049 (0) 70701295568

Gabriel Willmann ${ }^{1,2, \#}$, Iliya V Ivanov ${ }^{3,5}$, Manuel D Fischer ${ }^{3}$, Sukhamay Lahiri ${ }^{1,}$, Rohit K Pokharel $^{4}$, Annette Werner ${ }^{3}$ and Tejvir S Khurana ${ }^{1}$

${ }^{1}$ Department of Physiology, Pennsylvania Muscle Institute, University of Pennsylvania, Philadelphia, USA

${ }^{2}$ Eye Hospital and ${ }^{3}$ Institute for Ophthalmic Research, Centre for Ophthalmology, University of Tübingen, Tübingen, Germany

${ }^{4}$ Department of Orthopedics, Tribhuvan University, Kathmandu, Nepal

${ }^{5}$ McGill Vision Research, Dept. of Ophthalmology, McGill University, Montreal, Quebec, Canada

${ }^{\#}$ Corresponding Author

"Deceased May 2009

keywords—colour vision, hypoxia, high altitude, tritan axis, Cambridge Colour Test ${ }^{\circledR}$

Word count: 2550 


\section{Abstract}

Aim: To investigate changes in colour discrimination as a result of chronic hypoxic exposure induced by extreme altitudes (above $8000 \mathrm{~m}$ ) during an expedition to Mt. Everest.

Methods: Colour discrimination thresholds for tritan, protan and deutan axes were measured extensively in two male participants (four eyes) during an expedition to Mt. Everest, using a quantitative, computer controlled psychophysical colour vision test (modified version of the Cambridge Colour $\operatorname{Test}^{\circledR}$ ). The tests were carried out over a period of 54 days at altitudes of $1300 \mathrm{~m}, 3450 \mathrm{~m}, 4410 \mathrm{~m}, 5060 \mathrm{~m}, 5300 \mathrm{~m}, 6450 \mathrm{~m}$, $7200 \mathrm{~m}$ and $8000 \mathrm{~m}$.

Results: Colour vision tests one week before and six months after the expedition indicated normal colour discrimination in both participants. With increasing altitude, colour discrimination thresholds were found to rise, predominantly for the tritan (blue) axes in both observers. Deutan (green) thresholds were minimally elevated at high altitude, whereas protan (red) was altered in one observer. Tritan colour discrimination thresholds decreased as a function of time spent at a given altitude and normalised upon return to low altitude.

Conclusions: Chronic hypoxia induced by high altitude exposure transiently affects colour discrimination, in particular tritan axis discrimination. Decreased tritan discrimination is partly reversible upon physiological adaptation to high altitude and completely normalised upon return to low altitude. 


\section{Introduction}

Hypoxia has been implicated in the development of ophthalmological diseases such as diabetic retinopathy, central retinal artery occlusion and glaucoma, and is also known to affect visual functions including colour vision.[1-3] Indeed, the issue of changes to colour vision due to hypoxia in healthy individuals has been investigated since the early part of the last century, under both laboratory conditions as well as during exposure to high altitude, however, studies have been equivocal regarding whether changes occur and if so the nature of these changes.[4-8] Previous studies used a variety of acute and chronic hypoxic exposures and methods for analyzing colour vision including colour matching (anomaloscope), colour ordering (desaturated D1 panels, American Optical HRR plates, the Farnsworth-Munsell 100-Hue test) and colour discrimination (Mollon-Reffin-Minimalist test).[2, 6-10] Some studies have reported declines limited to the red-green chromatic axis, while others have found a greater decline in the tritan axis.[5, 8, 9, 11-13] To clarify these issues we investigated the effects of prolonged high altitude hypoxia on colour vision, by using a highly sensitive colour discrimination test during an ascent to Mt. Everest. The test, based on the Mollon-Reffin-Minimalist test, enabled accurate testing of discrimination along the tritan, deutan and protan axes in an unbiased fashion. To determine the effects of long term exposure and adaptation to high altitude, colour discrimination was tested repeatedly over a period of 54 days at various altitudes on the mountain. To our knowledge these are the first detailed measurements of this kind up to $8000 \mathrm{~m}$. 


\section{Materials and methods}

\section{Subjects}

Two healthy subjects (male, ages 32 - observer A and 46 years - observer B) took part in the experiments on Mt. Everest in 2008. They were accustomed to living at $11 \mathrm{~m}$ above sea level (Philadelphia, PA, USA) and were experienced mountaineers (over 20 years experience each), including numerous high altitude ascents; neither had reported any high altitude related illnesses such as high altitude pulmonary edema or high altitude cerebral edema in the past. An ophthalmic screening prior to the expedition was performed and neither subject had been objected to any kind of eye surgery prior to the field study; normal funduscopic examination, ocular movements, pupillary reactions and visual acuity were assessed (observer A: refractive error: right eye $-0.5,0,0$ with best corrected vision: 1.25 and left eye $-0.75,-$ $0.25,35^{\circ}$ with best corrected vision 1.6 ; observer $B$ : refractive error: right eye $6.5,0.5,90^{\circ}$ with best corrected vision 1.0 and left eye $-6.0,0,0$ with best corrected vision 1.0). No ophthalmic or other medical prescriptions were taken throughout the study period, but acetylsalicylic acid and Ginkgo biloba (each 100mg o.d.) were used. These two drugs are known not to interfere with colour vision. During the summit push supplementary oxygen was used for the night at Camp3 (7200m) and above. Oxygen flow varied from $0.5-2 \mathrm{l} / \mathrm{min}$. Overall, due to adhering to a conservative acclimatization protocol (see ascent profile in fig 1), both climbers acclimatized well. Clinical signs or symptoms of subacute or acute mountain sickness, high altitude pulmonary or cerebral edema were not encountered.

\section{Material}


Colour vision was tested using a computer controlled discrimination test which was presented on a calibrated (Spyder2Pro ${ }^{\circledR}$, Datacolor, Lawrenceville, NJ) LCD screen (Eee PCTM, 8 bit colour resolution, $1024 \times 768$ pixel spatial resolution; ASUS Tek COMPUTER Inc., Taiwan). The laptop was placed in a dark tent and tests were performed with no further illumination source. To ensure uniform testing conditions the laptop was warmed up to body temperature during the dark adaptation time in the sleeping bag and subjects viewed the stimuli from a distance of $80 \mathrm{~cm}$. Colour vision was tested using a modified version of the Cambridge Colour Test (Cambridge Research Systems Ltd., Rochester, UK).[14]

\section{Stimuli}

The stimulus consisted of the letter "C", presented on a multicoloured background, whereby the mean chromaticity was achromatic with CIE UCS coordinates: u' = $0.1977, v^{\prime}=0.4689$. The colour of the test-figure was varied along one of three chromatic axes and defined as the tritan- , protan- and deutan confusion lines (u'v' coordinates of their respective converging points: tritan: $u^{\prime}=0.257, v^{\prime}=0$; protan: $u^{\prime}$ $=0.678, v^{\prime}=0.501$; deutan: $\left.u^{\prime}=-1.217, v^{\prime}=0.782\right)$. Both figure and background were composed of dots of different sizes and luminance (ranging between 2 and $16 \mathrm{~cd} / \mathrm{m}^{2}$ ) with identical mean size and luminance for figure and background. Therefore, the figure was only discriminable from the background by means of chromatic contrast. The luminance of the dots varied randomly from trial to trial. Colour discrimination was quantified by determining discrimination thresholds, which were defined by the least discriminable chromatic contrast between figure and background. The thresholds were computed in units of the CIE (1976) $L^{*} u^{*} v^{*}$ colour space.[15] To determine each threshold, 117 different contrasts $\left(C_{\max }=0.07\right.$ units, $C_{\min }=0.002$ units) were presented in a decreasing order in steps of 0.001 units. Altogether 352 
different stimuli were presented, each within a 3s time interval. All stimuli were generated and presented using a custom-software developed in $\mathrm{C}++$.

\section{Experimental Procedure}

Each session commenced with dark adaptation for $30 \mathrm{~min}$ followed by a $10 \mathrm{~min}$ adaptation to the background used in this study. The subjects' task was to indicate the orientation of the gap of each presented figure "C" (left, right, up, down), by pressing one of four arrow cursors on the laptop. Average duration of each test was 15 minutes; one session (4 tests) was completed after 1 hour for both observers as each eye was tested separately.

Control measurements were taken in Philadelphia one week prior to and 6 months after the expedition. The first measurements at elevated altitude were taken in Kathmandu (1300m), the following measurements were performed at $3450 \mathrm{~m}, 4410 \mathrm{~m}$, $5060 \mathrm{~m}, 5300 \mathrm{~m}, 6450 \mathrm{~m}, 7200 \mathrm{~m}$ and $8000 \mathrm{~m}$ over a period of 54 days according to the ascent protocol.

During the expedition, the mountaineers wore UV protection sunglasses (Julbo Inc., Williston and Opticus, Boulder, USA) during daytime. Experiments were conducted with well rested subjects at least 4 hours after sunset.

\section{Data Analysis}

The discrimination thresholds were calculated by determining the least discriminable chromatic contrast between background and figure, for each colour region and for each confusion line. The cut-off was defined as the threshold just prior to three consecutive false responses. Chromatic contrast was calculated using the CIE 1976 $\Delta \mathrm{E}^{*} \mathrm{uv}$ colour difference formula.[15] 
Statistical significance was set at $p<0.05$. SPSS ${ }^{\circledR}$ version 16.0 for Windows ${ }^{\circledast}\left(\right.$ SPSS $^{\circledR}$ Chicago, IL) was used for statistical analysis of correlation (Pearson r) and linear regression $\left(r^{2}\right)$.

\section{Results}

Discrimination along all three colour axes prior and 6 months after the climb on Mt. Everest was found to be within the normal range (observer A: tritan $0.0078, S D \pm$ 0.00084 , deutan $0.003, S D \pm 0.0013$, protan $0.0032, S D \pm 0.00084, n=5$; observer B: tritan $0.012, S D \pm 0.0012$, deutan $0.009, S D \pm 0.0027$, protan $0.0118, S D \pm$ $0.0015, n=5)$. These values served as baseline for comparison with discrimination recorded at increasing altitudes.

To understand the effect of high altitude on colour discrimination over the course of the expedition (54days), the thresholds for each observer were calculated and compared to the climbers' ascent line on Mt Everest. Fig 1 clearly demonstrates how tritan but not protan and deutan discrimination correlates with the climbers' exposure to high altitude. At $1300 \mathrm{~m}$ on day 1 , only observer A (fig 1 A) showed a minimal increase in the tritan threshold compared to control tests, but at an altitude of $3450 \mathrm{~m}$ on day 3 both observers showed obvious changes in the tritan axis, which became even more apparent with further altitude gain. As the climbers descended from Camp2 at $6450 \mathrm{~m}$ to $4300 \mathrm{~m}$ on day 23 to recuperate and acclimatize, the colour vision threshold for tritan mirrored the climbers' descent and dropped. The second peak in the tritan axis was reached at the second acclimatization step to Camp3 at $7200 \mathrm{~m}$. During the following rest period to regain strength for the summit push between day 32 and 41 at $5300 \mathrm{~m}$ the tritan threshold again dropped only to reach its absolute peak at $8000 \mathrm{~m}$ despite the use of supplementary oxygen. Upon descent to 
low altitude, the threshold for tritan dropped quickly and measurements taken 6 months after the expedition were within the normal range. The changes seen for deutan and protan did not behave in the same manner during the ascent to high altitude. Deutan and protan threshold levels were overall elevated at high altitude compared to control measurements in observer A (fig $1 \mathrm{~A}$ ), but never to the same extent as tritan. In contrast to tritan, no elevated thresholds were visible for either deutan or protan at measurements taken at $7200 \mathrm{~m}$ and $8000 \mathrm{~m}$ during the summit push with the use of supplementary oxygen. Observer B (fig 1B) showed very little or no changes in deutan and protan.

To describe the effect of high altitude on colour vision, all first measurements after arriving at a new altitude between $1300 \mathrm{~m}$ and $8000 \mathrm{~m}$ were taken into account. Fig $2 A$ and $B$ show the discrimination thresholds for all altitudes tested during the ascent to Mt. Everest for each observer separately. A logarithmic decrease in tritan discrimination with increasing altitude is observed (Pearson-Correlation for tritan: observer A: $r=0.95, p<0.0001$; observer $B: r=0.93, p=0.001)$. Tritan discrimination still increased even with the use of supplementary oxygen at highest altitudes tested. In contrast, protan and deutan thresholds, did not correlate with altitude gain per se (Pearson-Correlation for deutan: observer $A: r=0.02, p=0.97$; observer $\mathrm{B}: \mathrm{r}=0.06, \mathrm{p}=0.89$ and protan: observer $\mathrm{A}: \mathrm{r}=-0.07, p=0.86$; observer $\mathrm{B}$ : $r=0.23, p=0.58$ ). Calculation of linear regression coefficients (fig $2 \mathrm{C}$ ) confirmed a strong correlation between altitude increase and tritan thresholds $\left(r^{2}\right.$ linear $\left.=0.82\right)$, and no correlation between altitude increase and protan $\left(r^{2}\right.$ linear $\left.=1.64 \mathrm{E}^{-5}\right)$ or deutan $\left(r^{2}\right.$ linear $\left.=0.025\right)$ thresholds for observer $A$ and $B$.

To determine the overall changes of colour vision at high compared to low altitude, two high altitude levels $(5300 \mathrm{~m}$ and $6450 \mathrm{~m})$ were chosen to perform multiple tests. As described in fig $3 \mathrm{~A}$, tritan thresholds increased significantly for both observers at 
$5300 \mathrm{~m}$ and $6450 \mathrm{~m}$ compared to control measurements (tritan: observer A: $p 5300 \mathrm{~m}=$ 0.02 and $\mathrm{p} 6450 \mathrm{~m}=0.001$; observer B: $\mathrm{p} 5300 \mathrm{~m}=0.01$ and $\mathrm{p} 6450 \mathrm{~m}=0.02)$. Deutan and protan changed significantly in observer A (deutan: p5300m $=0.002$ and $\mathrm{p} 6450 \mathrm{~m}=0.001 ;$ protan: $\mathrm{p} 5300 \mathrm{~m}=0.001$ and $\mathrm{p} 6450 \mathrm{~m}=0.01)$ at both altitudes compared to control. Observer B showed a similar trend of increase in deutan at $5300 \mathrm{~m}$, which reached statistical significance at $6450 \mathrm{~m}(\mathrm{p} 6450 \mathrm{~m}=0.03)$ compared to control. No significant change for the protan axis was seen in observer B.

To evaluate the effect of physiological adaptation (acclimatization) to high altitude on colour vision changes, the threshold levels measured for each axis at $5300 \mathrm{~m}$ and $6450 \mathrm{~m}$ were compared over time. As described in fig $3 \mathrm{~B}$ for tritan, the first measurement after arriving at an altitude of $5300 \mathrm{~m}$ and $6450 \mathrm{~m}$ revealed the highest threshold for tritan in both observers. Consecutive testing on day 1, 2, 12 and 25 at $5300 \mathrm{~m}$ and day $1,10,16$ and 18 at $6450 \mathrm{~m}$ showed a decrease in the tritan threshold over time as the observers acclimatized. Deutan and protan did not show a decline of thresholds over time (data not shown).

\section{Discussion}

Here we show colour vision changed due to the effects of high altitude hypoxia during a mountaineering expedition above $8000 \mathrm{~m}$ on Mt. Everest. We used the Cambridge Colour $\operatorname{Test}^{\circledR}$, which proved to be a reliable and highly sensitive tool to detect these changes. Important differences between discrimination along the different colour axes were observed: the decrease in tritan discrimination correlated well with increasing altitude, and was found to be partly reversible upon adaptation to high altitude. Overall, changes in deutan and protan were minimal compared to the changes seen in tritan, indicating that tritan is predominantly altered at high altitude. 
High altitude hypoxia can trigger changes in colour discrimination. Previous studies have reported changes along the tritan axis for simulated or high altitude hypoxia using various colour vision tests and testing conditions, which is consistent with our findings.[5, 8, 9] Interestingly, tritan discrimination shadowed the line of ascent of both observers. It is important to point out, that tritan discrimination continued to decrease despite using supplementary oxygen during the measurements taken at $7200 \mathrm{~m}$ and $8000 \mathrm{~m}$. This is not surprising in view of recent data that oxygen saturation is not completely restored even using supplementary oxygen above 7200m.[16] We hypothesize that this decrease would potentially be even higher at extreme altitudes without supplementary oxygen, as oxygen saturation dramatically drops at these extreme altitudes. $[17,18]$

What causes this decrease in colour vision at high altitude and predominantly in the tritan axis? Evidence regarding the predominant effect of chronic hypoxia on discrimination along the tritan axis suggests a selective vulnerability of $S$ cone compared to L or M cone pathways.[19] Changes in colour discrimination along the tritan axis are found early on in common retinal diseases such as diabetes or in less common hereditary eye disorders e. g. autosomal dominant optic atrophy.[20-22] S cones may be particularly sensitive because of their relatively low abundance: only 5 - $10 \%$ of all cones are S cones.[23] Hypoxia decreases the maximum response rate of all cone pathways equally, however, as the number of $S$ cones is limited, their absolute responses might become undetectable at earlier stages compared to the more redundant $\mathrm{L}$ or $\mathrm{M}$ cones.[24] While hypoxia-induced cone dysfunction is likely to be the cause for decreased colour vision, other factors may play a role: the use of sunglasses required to prevent high altitude UV light damage may result in a long lasting chromatic adaptation to middle and long wavelength stimuli, which in turn may attenuate the potential effects on deutan and protan at high altitude.[25, 26] Indeed it 
would be important to rigorously investigate the existence and mechanism(s) of adaptation of chromatic threshold due to the prolonged stay at high altitude in larger studies. Additionally, we cannot rule out involvement of the higher order neurons involved with processing of colour vision. Indeed, we are currently designing experiments to test these possibilities. We are aware of the age difference of the two mountaineers. Older age can contribute to higher thresholds in the tritan axis and indeed observer B (age 46) yielded slightly higher scores for all three axes at low and high altitude.[14] However, both observers' revealed concordant measurements over time and altitude. It is important to mention that in contrast to previous studies at high altitude, all tests were performed under mesopic conditions, as illuminant changes have to be taken into account at high altitude.[27]

We conclude that high and extreme altitude hypoxia adversely affects colour vision predominantly along the tritan axis. These data have important implications for patients where hypoxia is noted clinically and for optimizing the choice of colour used in displays of devices such as compasses, altimeters and global positioning system receivers that are often critical for aviation and mountaineering situations where hypoxia may be a confounding variable. We suggest that physiological adaptation to high altitude by proper acclimatization helps to reduce this deficit in blue discrimination and that all colour vision changes seen at high altitude are reversible and transient in nature upon descent to low altitude.

\section{Footnotes}

\section{Acknowledgements:}

We dedicate this article to the memory of Prof. Sukhamay Lahiri and his pioneering work in high altitude research in the Himalayas. We are grateful for Nepalese Health 
Research Council (NHRC) for help in obtaining research permits and highly appreciate the support from the Muscular Dystrophy Foundation (MDF) Nepal. We would also like to thank Andreas Kögel (Institute Schreier, Germany) for statistical advice. We thank the reviewers for their constructive criticism and helpful suggestions that have improved the manuscript.

\section{Competing interest:}

None declared.

\section{Funding:}

Funded in part by grants from World Anti-Doping Agency (WADA) to Prof. Lahiri \& Khurana.

\section{Ethics committee approval:}

Obtained.

\section{Copyright licence statement:}

"I Gabriel Willmann The Corresponding Author of this article (the Contribution") has the right to grant on behalf of all authors and does grant on behalf of all authors, a licence to the BMJ Publishing Group Ltd and its licensees, to permit this Contribution (if accepted) to be published in British Journal of Ophthalmology (BJO) and any other BMJ Group products and to exploit all subsidiary rights, as set out in our licence set out at: (http://bjo.bmj.com//ifora/licence.pdf). 


\section{References}

1 Ernest JT, Krill AE. The effect of hypoxia on visual function. Psychophysical studies. Invest Ophthalmol. 1971;10: 323-328.

2 Vingrys AJ, Garner LF. The effect of a moderate level of hypoxia on human color vision. Doc Ophthalmol. 1987;66: 171-185.

3 Linsenmeier RA, Braun RD, McRipley MA, et al. Retinal hypoxia in long-term diabetic cats. Invest Ophthalmol Vis Sci. 1998;39: 1647-1657.

4 Wilmer WH, Berens C, Jr. Medical studies in aviation: V. The effect of altitude on ocular functions. Aviat Space Environ Med. 1918;60: 1018-1023.

5 Smith VC, Ernest JT, Pokorny J. Effect of hypoxia on FM 100-Hue test performance. Mod Probl Ophthalmol. 1976;17: 248-256.

6 Richalet JP. The French scientific expedition to Numbur, autumn 1981. Prog Clin Biol Res. 1983;136: 189-195.

7 Leid J, Campagne JM. Colour vision at very high altitude. Color Res Appl. 2001;26 Suppl 1: S281-283.

8 Tekavcic-Pompe M, Tekavcic I. Color vision in the tritan axis is predominantly affected at high altitude. High Alt Med Biol. 2008;9: 38-42.

9 Karakucuk S, Oner AO, Goktas S, et al. Color vision changes in young subjects acutely exposed to 3,000 m altitude. Aviat Space Environ Med. 2004;75: 364-366.

10 Mollon JD, Astell S, and Reffin JP. A minimalist test of colour vision. Colour Vision Deficiencies. 1991;X: 59-67.

11 Richalet JP, Duval-Arnould G, Darnaud B, et al. Modification of colour vision in the green/red axis in acute and chronic hypoxia explored with a portable anomaloscope. Aviat Space Environ Med. 1988;59: 620-623. 
12 Richalet JP, Rutgers V, Bouchet $\mathrm{P}$, et al. Diurnal variations of acute mountain sickness, colour vision, and plasma cortisol and ACTH at high altitude. Aviat Space Environ Med. 1989;60: 105-111.

13 Richalet JP, Robach P, Jarrot S, et al. Operation Everest III (COMEX '97). Effects of prolonged and progressive hypoxia on humans during a simulated ascent to 8,848 M in a hypobaric chamber. Adv Exp Med Biol. 1999;474: 297-317.

14 Regan BC, Reffin JP, Mollon JD. Luminance noise and the rapid determination of discrimination ellipses in colour deficiency. Vision Res. 1994;34: 1279-1299.

15 Wyszecki G, \& Stiles WS. Color science: concepts and methods, quantitative data and formulae. New York: Wiley. 1982;2nd ed.: 723.

16 Grocott MP, Martin DS, Levett DZ, et al. Arterial blood gases and oxygen content in climbers on Mount Everest. N Engl J Med. 2009;360: 140-149.

17 West JB. Adventures in high-altitude physiology. Adv Exp Med Biol. 2006;588: 716.

18 Bosch MM, Merz TM, Barthelmes D, et al. New insights into ocular blood flow at very high altitudes. J Appl Physiol. 2009;106: 454-460.

19 Hood DC, Benimoff NI, Greenstein VC. The response range of the blue-cone pathways: a source of vulnerability to disease. Invest Ophthalmol Vis Sci. 1984;25: 864-867.

20 North RV, Cooney O, Chambers D, et al. Does hyperglycaemia have an influence upon colour vision of patients with diabetes mellitus? Ophthalmic Physiol Opt. 1997;17: 95-101.

21 Volbrecht VJ, Schneck ME, Adams AJ, et al. Diabetic short-wavelength sensitivity: variations with induced changes in blood glucose level. Invest Ophthalmol Vis Sci. 1994;35: 1243-1246. 
22 Jaeger W, Fruh D, Lauer HJ. Types of acquired colour deficiencies caused by autosomal-dominant infantile optic atrophy. Mod Probl Ophthalmol. 1972;11: 145147.

23 Hofer $\mathrm{H}$, Carroll J, Neitz J, et al. Organization of the human trichromatic cone mosaic. J Neurosci. 2005;25: 9669-9679.

24 Greenstein VC, Hood DC, Ritch R, et al. S (blue) cone pathway vulnerability in retinitis pigmentosa, diabetes and glaucoma. Invest Ophthalmol Vis Sci. 1989;30: $1732-1737$.

25 Eisner A, Enoch JM. Some effects of 1 week's monocular exposure to longwavelength stimuli. Percept Psychophys. 1982;31: 169-174.

26 Neitz J, Carroll J, Yamauchi Y, et al. Color perception is mediated by a plastic neural mechanism that is adjustable in adults. Neuron. 2002;35: 783-792.

27 Daumann FJ, Draeger J. Aviation and space flight ophthalmology. Ophthalmologe. 1993;90: 380-386.

\section{Figure Legends}

Figure 1. Overview of the timeline of altitude exposure and altered colour thresholds on Mt. Everest.

Overview of an ascent to high altitude above $8000 \mathrm{~m}$ on Mt. Everest (black line), where colour discrimination thresholds along tritan, deutan and protan axes (blue, dotted green and red lines) were determined at different high altitude points over a period of 54 days with the highest measurement taken at $8000 \mathrm{~m}$ for each observer $A$ and $\mathrm{B}$. The colour discrimination threshold for tritan increased significantly with altitude gain and correlated well with the degree of high altitude exposure and a 
subsequent drop in oxygen saturation. The oxygen concentration drops rapidly to about $8 \%$ at $8000 \mathrm{~m}$ compared to $21 \%$ of oxygen at sea level. Note that as both observers used supplemental oxygen above $7200 \mathrm{~m}$, the oxygen concentration scale shown for a given altitude does not accurately reflect the actual oxygen saturation of observers above this altitude. Colour vision for deutan (both observers) and less for protan (only observer A) was minimally decreased at high altitude compared to baseline. Control measurements were taken one week before (shown as day -7) and six months after (shown as day 180) the expedition showing normal colour vision thresholds in all three axes.

$\Delta \mathrm{E}^{*} \mathrm{uv}$ refers to the mean chromatic difference between background and figure and is calculated by the $\operatorname{CIE}(1976)$ colour difference formula $\Delta E\left(L^{*} u^{*} v^{*}\right)$.

Figure 2. Correlation and regression analysis of colour discrimination and altitude.

(A and B) The threshold for tritan discrimination is increased significantly (left: observer A; right: observer B) with increasing altitude in contrast to deutan and protan. The first measurement taken at a given altitude from $1300 \mathrm{~m}$ to $8000 \mathrm{~m}$ is shown. Interestingly, despite the use of supplementary oxygen at altitudes of $7200 \mathrm{~m}$ and $8000 \mathrm{~m}$ (marked by ${ }^{*}$ ) the threshold for tritan increased in both observers, whereas deutan and protan remained at the same level or even dropped. Observer A: Pearson-Correlation $r$ for tritan $=0.95$, deutan $=0.02$ protan $=-0.07$; observer $B$ : Pearson-Correlation $r$ for tritan $=0.93$, deutan $=0.06$ protan $=0.23$.

(C) Linear regression comparing colour discrimination in regard to altitude gain shown for tritan, deutan and protan for both observers. Linear regression for tritan 
correlates well with altitude gain $\left(r^{2}\right.$ linear $\left.=0.82\right)$. Deutan $\left(r^{2}\right.$ linear $\left.=0.025\right)$ and protan $\left(r^{2}\right.$ linear $\left.=1.64 \mathrm{E}^{-5}\right)$ showed no such correlation.

Figure 3. Bargraph demonstrating temporal changes in colour discrimination due to acclimatization.

(A) illustrates colour vision changes at $5300 \mathrm{~m}$ and $6450 \mathrm{~m}$ compared to control where

iterative testing was performed over time for observer A and B. Tritan thresholds increased significantly for both observers at $5300 \mathrm{~m}$ and $6450 \mathrm{~m}$; deutan and protan thresholds changed significantly in observer A compared to control measurements. Observer B showed a significant increase in the deutan threshold at $6450 \mathrm{~m}$, a trend at $5300 \mathrm{~m}$ and no change in the protan axis. *indicates statistically significant changes; $p<0.05(n 100 m=5, n 5300 m=5, n 6450 m$ observer $A=4$ and $n 6450 m$ observer $\mathrm{B}=3$ ).

(B) shows colour discrimination along the tritan axis at altitudes of $5300 \mathrm{~m}$ and $6450 \mathrm{~m}$ compared to controls for both observers over time spent at respective altitudes. The first measurement was taken when altitudes of $5300 \mathrm{~m}$ or $6450 \mathrm{~m}$ were reached for the first time and revealed the highest threshold for tritan. Over time, as the mountaineers acclimatized, the thresholds for tritan decreased in both observers. Deutan and protan did not show a drop in thresholds over time (data not shown). One measurement was taken per subject on the respective days.

Only one observer performed measurement D: 6450m day 18.

\section{Supplemental Figure 1. Test stimuli.}

(a) deutan contrast (b) protan contrast, (c) tritan contrast. Shown are maximum contrast values. 


\section{Figure 1}

A)

$6.5 \% \mathrm{O}_{2}^{*}$
$7.8 \% \mathrm{O}_{2}{ }^{*}$
$9 \% \mathrm{O}_{2}{ }^{*}$
$10 \% \mathrm{O}_{2}$
$11.5 \mathrm{O}_{2}$
$13 \% \mathrm{O}_{2}$
$14.8 \% \mathrm{O}_{2}$
$16.6 \% \mathrm{O}_{2}$
$18.7 \% \mathrm{O}_{2}$
$21 \% \mathrm{O}_{2}$

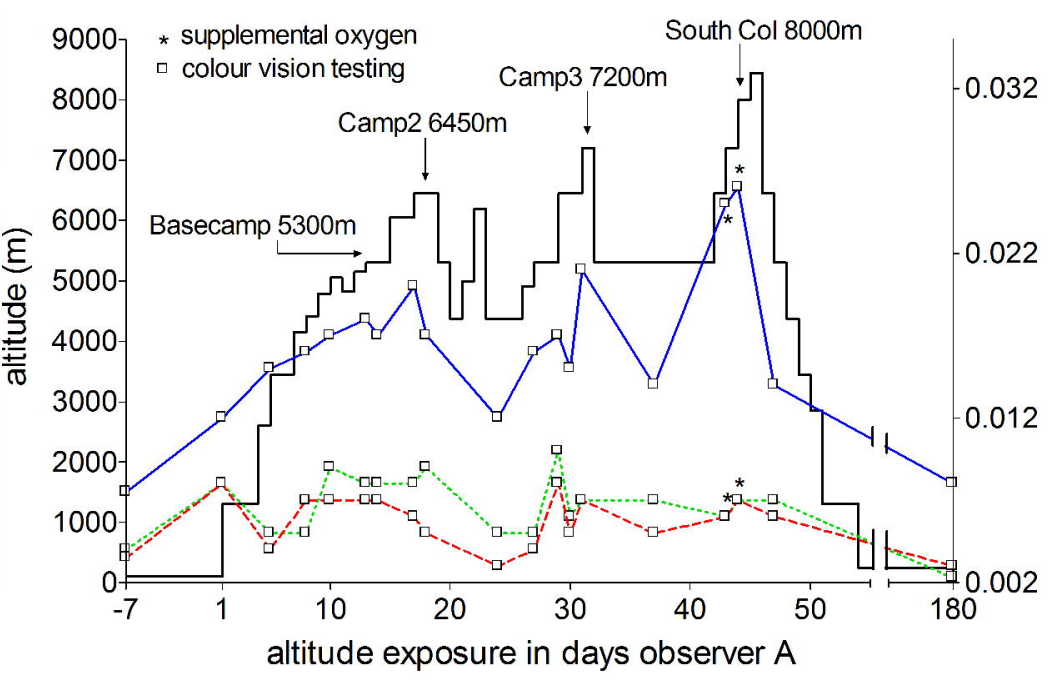

B)

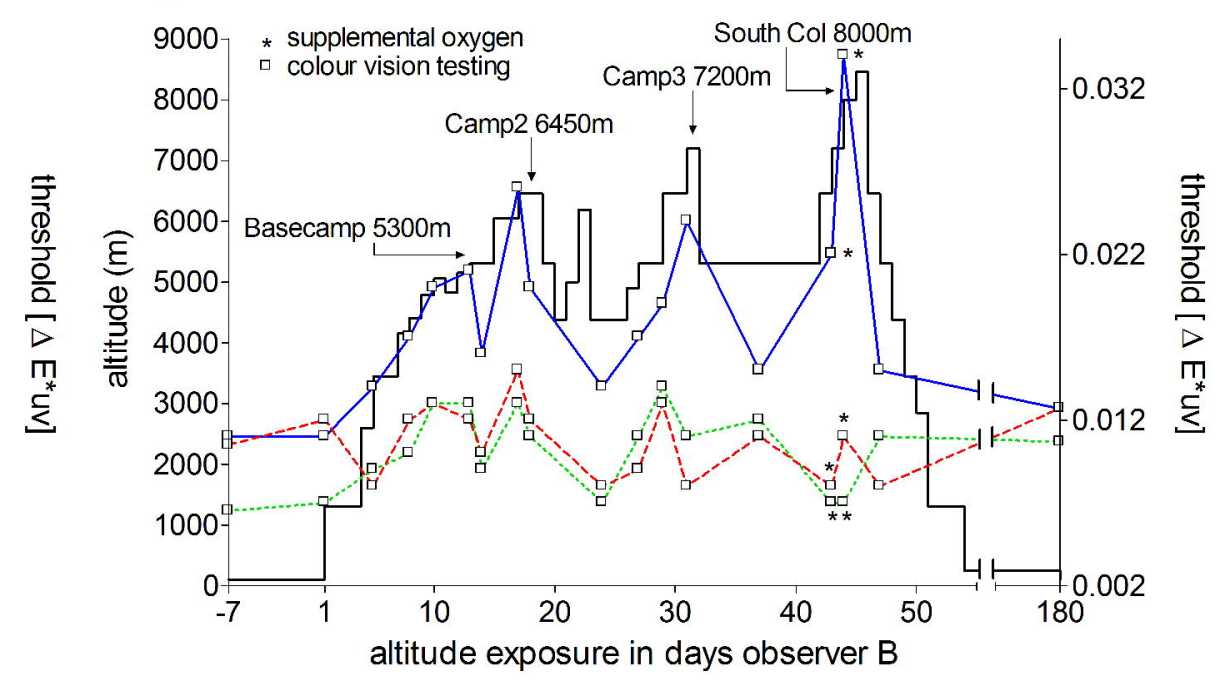




\section{Figure 2}

A)

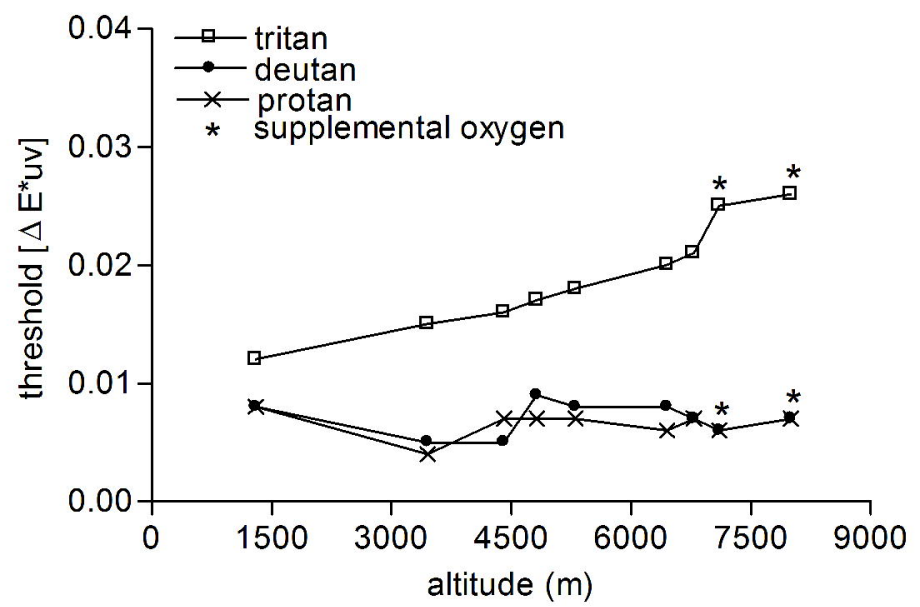

B)

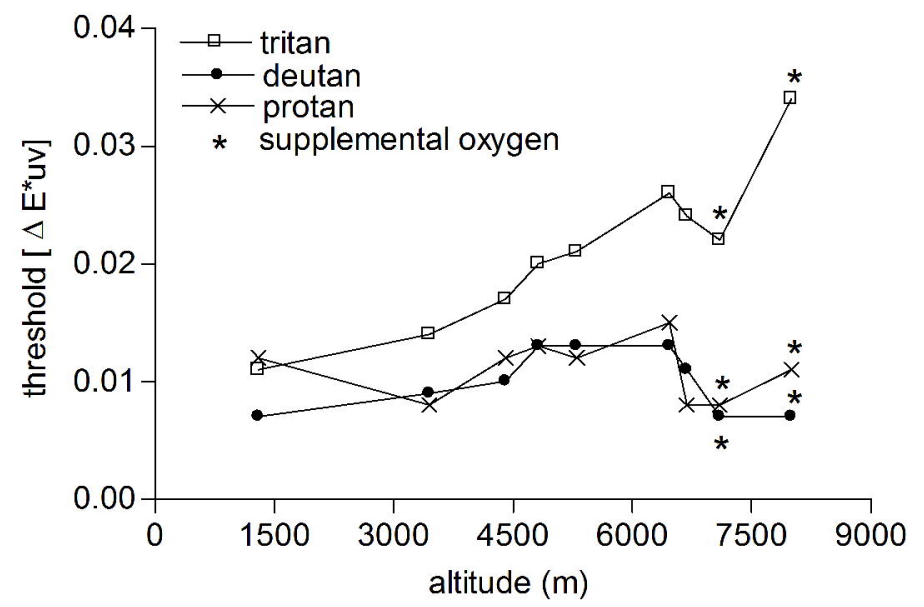

C)
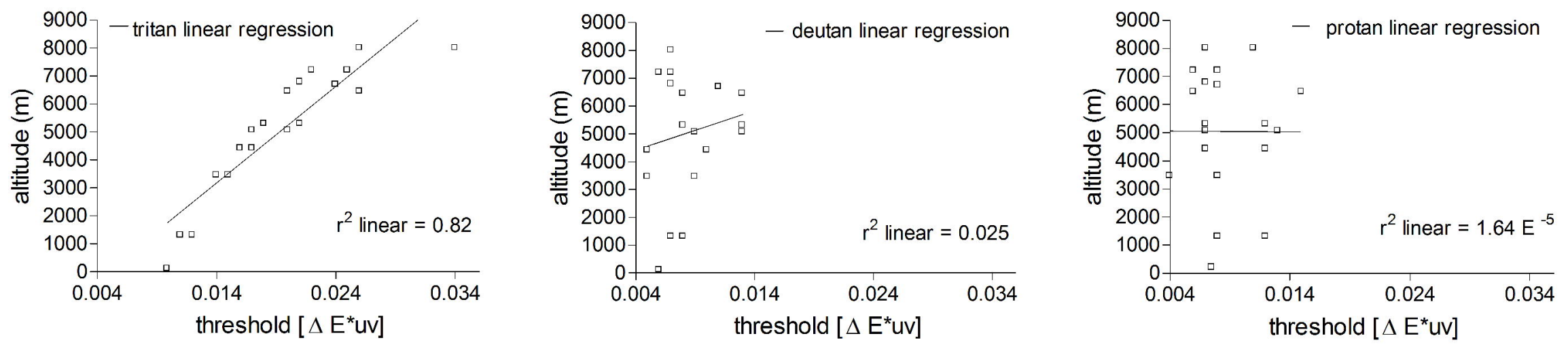


\section{Figure 3}

A)

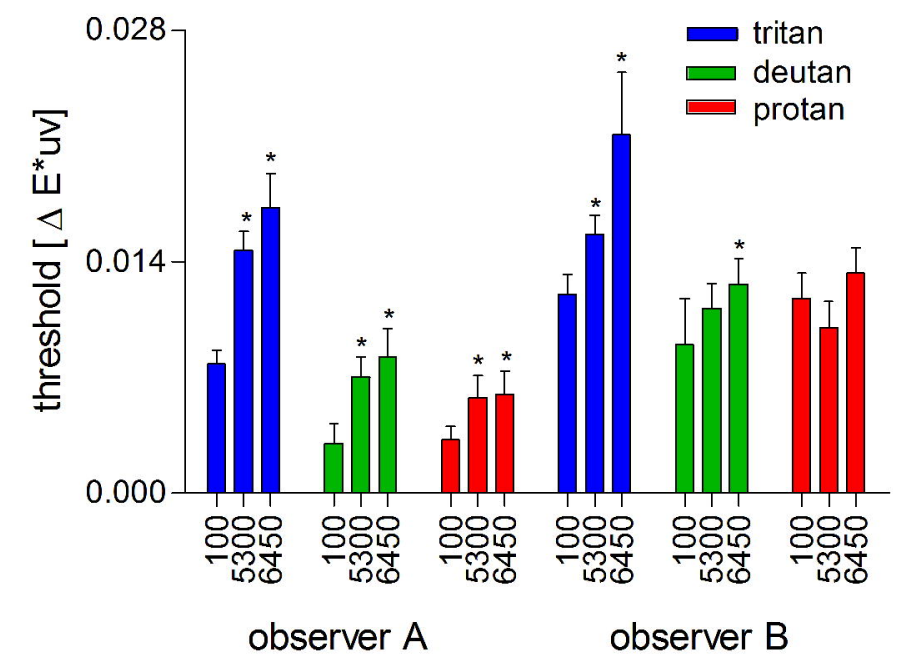

B)

tritan at 5300 and 6450 m upon acclimatization

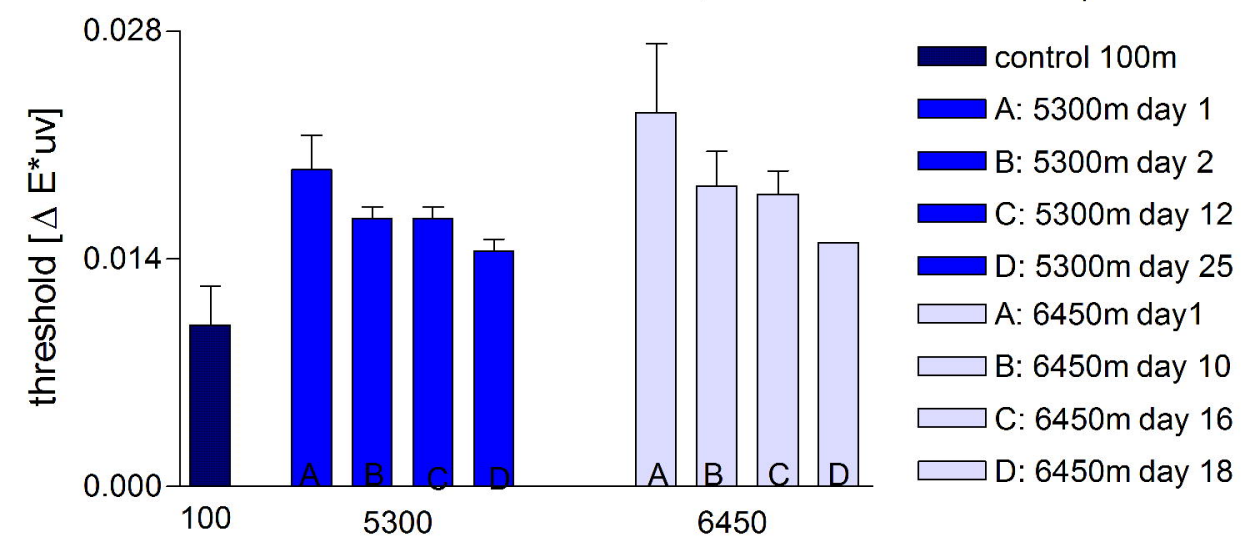

altitude (m) 